\title{
Review of eprodisate for the treatment of renal disease in $\mathrm{AA}$ amyloidosis
}

This article was published in the following Dove Press journal: International Journal of Nephrology and Renovascular Disease 23 February 2012

Number of times this article has been viewed

\author{
Adam Rumjon' \\ Thomas Coats' \\ Muhammad $M$ Javaid ${ }^{2}$ \\ 'Department of Nephrology, King's \\ College Hospital NHS Foundation \\ Trust, London, ${ }^{2}$ Department of \\ Nephrology, Dartford and Gravesham \\ NHS Trust, Darent Valley Hospital, \\ Dartford, UK
}

\begin{abstract}
Secondary (AA) amyloidosis is a multisystem disorder complicating chronic infections or inflammatory diseases. It is characterized by extracellular deposit of fibrils composed of fragments of serum amyloid A (SAA), an acute phase reactant protein. The kidney is the most frequent organ involved, manifesting as progressive proteinuria and renal impairment. Attenuation of the level of circulating SAA protein by treating the underlying inflammatory condition remains the primary strategy in treating AA amyloidosis. However, at times, achieving adequate control of protein production can prove difficult. In addition, relapse of renal function often occurs rapidly following any subsequent inflammatory stimulus in patients with existing amyloidosis. Recently there has been an interest in finding other potential strategies targeting amyloid deposits themselves. Eprodisate is a sulfonated molecule with a structure similar to heparan sulfate. It competitively binds to the glycosaminoglycan-binding sites on SAA and inhibits fibril polymerization and amyloid deposition. Recent randomized clinical trial showed that it may slow down progressive renal failure in patients with AA amyloidosis. However confirmatory studies are needed and results of a second Phase III study are eagerly awaited to clarify whether or not eprodisate has a place in treating renal amyloid disease.
\end{abstract}

Keywords: AA amyloidosis, eprodisate, pathogenesis

\section{Introduction}

The amyloidoses are a group of heterogeneous, life-threatening diseases, characterized by the deposition of highly organized, insoluble protein aggregates within organs and normal tissue. The abnormal deposition of $\beta$-sheet fibrillar proteins results in either localized or systemic disease and can be hereditary or acquired in nature. In the systemic form of the disease, it is possible for deposits to occur in all tissues of the human body with the exception of the brain (this is seen in locally occurring amyloid deposits in Alzheimer's disease). The binding of Congo red stain to the $\beta$-pleated sheet emits a characteristic apple-green birefringence under polarized light, allowing a diagnosis of amyloidosis to be made.

To date, 28 structurally unrelated precursor proteins have been described that have the capacity to adopt a $\beta$-sheet structure. ${ }^{1}$ All of these proteins are naturally soluble, and through processes of cleavage, aggregation, and misfolding, form fibrils with an abnormal $\beta$-sheet morphology. ${ }^{2}$ The two most common precursor proteins implicated in the formation of amyloid proteins include monoclonal light chains leading to primary or AL amyloidosis, and serum amyloid A (SAA), which in turn causes secondary (reactive) or AA amyloidosis.
Correspondence: Muhammad M Javaid Darent Valley Hospital, Darenth Wood Road, Dartford, DA2 8DA, UK

$\mathrm{Tel}+44$ I32 2428417

$\mathrm{Fax}+441322428415$

Emailmmjavaid@doctors.org.uk 
AA amyloidosis mainly occurs as a result of chronic inflammatory states, such as rheumatoid arthritis, ankylosing spondylitis, or psoriatic arthritis but can also result from chronic infections, Familial Mediterranean Fever (FMF), or Crohn's disease (Table 1). Less commonly, Castleman's disease, vasculitis, and cancers have also been implicated. ${ }^{3}$ A recent single-center study detailing 20 years' Florentine experience of AA amyloidosis showed that rheumatoid arthritis contributed to $45 \%$ of cases and $67 \%$ of patients had some form of renal involvement. ${ }^{4}$ Other recent studies have shown that $5 \%-17 \%$ of patients with rheumatoid arthritis have amyloidosis reported as the cause of death. ${ }^{5}$ In a study of 374 patients with AA amyloidosis, Lachmann et al reported that patients can experience symptoms of inflammatory disease for a median duration of approximately 17 years before a diagnosis of amyloidosis is made. ${ }^{3}$

The kidney is the organ chiefly affected by AA amyloidosis, manifesting as progressive proteinuria, nephrotic syndrome, and renal dysfunction. ${ }^{3,6} \mathrm{Up}$ to $40 \%$ of patients with AA amyloidosis develop end stage renal failure. ${ }^{3}$ The complications arising as a result of renal failure are the cause of death in $40 \%-60 \%$ of cases, with a median survival after diagnosis of 4-8 years. ${ }^{7-9}$ Old age, end stage renal failure at presentation, reduced serum albumin level, and persistent higher levels of SAA concentration are associated with poor prognosis. ${ }^{3}$

Hepatic amyloid deposits are present in nearly a quarter of the patients affected with secondary amyloidosis. ${ }^{3}$ Gastrointestinal involvement, which manifests as diarrhea and malabsorption syndrome, is present in approximately $20 \%$ of patients. The incidence of gastrointestinal disease is increasing as the availability of renal replacement

Table I List of causes of AA amyloid in order of incidence

Rheumatoid arthritis
Juvenile idiopathic arthritis
Other chronic inflammatory arthritides
Bronchiectasis
Familial Mediterranean fever
Unknown cause
Crohn's disease
Other source of chronic sepsis (osteomyelitis, tuberculosis, etc)
Injection-drug abuse
Complications of paraplegia
Castleman's disease
TNF-receptor associated periodic fever syndrome
Neoplasia
Vasculitis
Muckle-Wells syndrome
Abbreviation: TNF, tumor necrosis factor.

therapy has led to the extension of patients' lives and their subsequent ability to accumulate increasing amounts of amyloid deposits. ${ }^{3,10}$

In contrast with primary (AL) amyloidosis, other clinical features such as thyroid, splenic, cardiac, and autonomic nerve involvement are less frequent. ${ }^{11}$ The survival rates have been shown to improve upon treatment of the underlying inflammatory condition. ${ }^{12-14}$

\section{Pathophysiology of AA amyloidosis}

The precursor SAA is a 104 -amino-acid protein that is produced in response to inflammatory stimuli but its exact function remains unclear. This is an acute phase reactant and is produced in the liver in response to pro-inflammatory cytokines, and can be up regulated by up to 1000 times during episodes of acute inflammation. ${ }^{15,16}$ The principal cytokines involved in SAA induction are tumor necrosis factor (TNF), interleukin 1 (IL-1), interleukin 6 (IL-6), transcription factors such as SAA activating factor (SAF-1), and lipopolysaccharide (LPS). ${ }^{17-19}$ In addition, it has also been demonstrated that hepatic clearance of SAA during episodes of inflammation (both acute and chronic) is reduced, hence the elevated levels witnessed. ${ }^{20}$

SAA is found in the serum as an apolipoprotein. ${ }^{21}$ Under normal circumstances it is degraded without the development of amyloid fibrils. ${ }^{22}$ In patients with amyloidosis however, the intermediate SAA products combine to form fibrils. These fibrils are deposited in the extracellular space of tissues and organs. Glycosaminoglycans such as heparan or dermatan sulfate, and serum amyloid P (SAP) then bind to these fibrils, which are then rendered invulnerable to degradation (Figure 1) ${ }^{23-25}$ However, not all patients with chronic inflammation develop this complication and it remains largely unclear why some patients are prone to develop secondary (AA) amyloidosis while the others are protected. Certain genetic factors have been shown to increase the propensity for developing amyloidosis, such as polymorphisms in the gene coding for SAA1. Patients who are homozygous for the SAA1 isotype have a three- to sevenfold increased risk of developing amyloidosis. ${ }^{26-28}$ Other factors such as matrix metalloproteinase proteins (MMP), isoprenoid metabolism, heat shock proteins, and cathepsin D have also been implicated in the pathogenesis of AA amyloidosis. ${ }^{29}$

The exact mechanism by which the deposits affect organ function is not well known. Clearly large deposits can distort the integrity and function of a tissue on a structural level. Whilst positive correlations exist between the size of amyloid deposits and disease severity, there is a variable relationship 


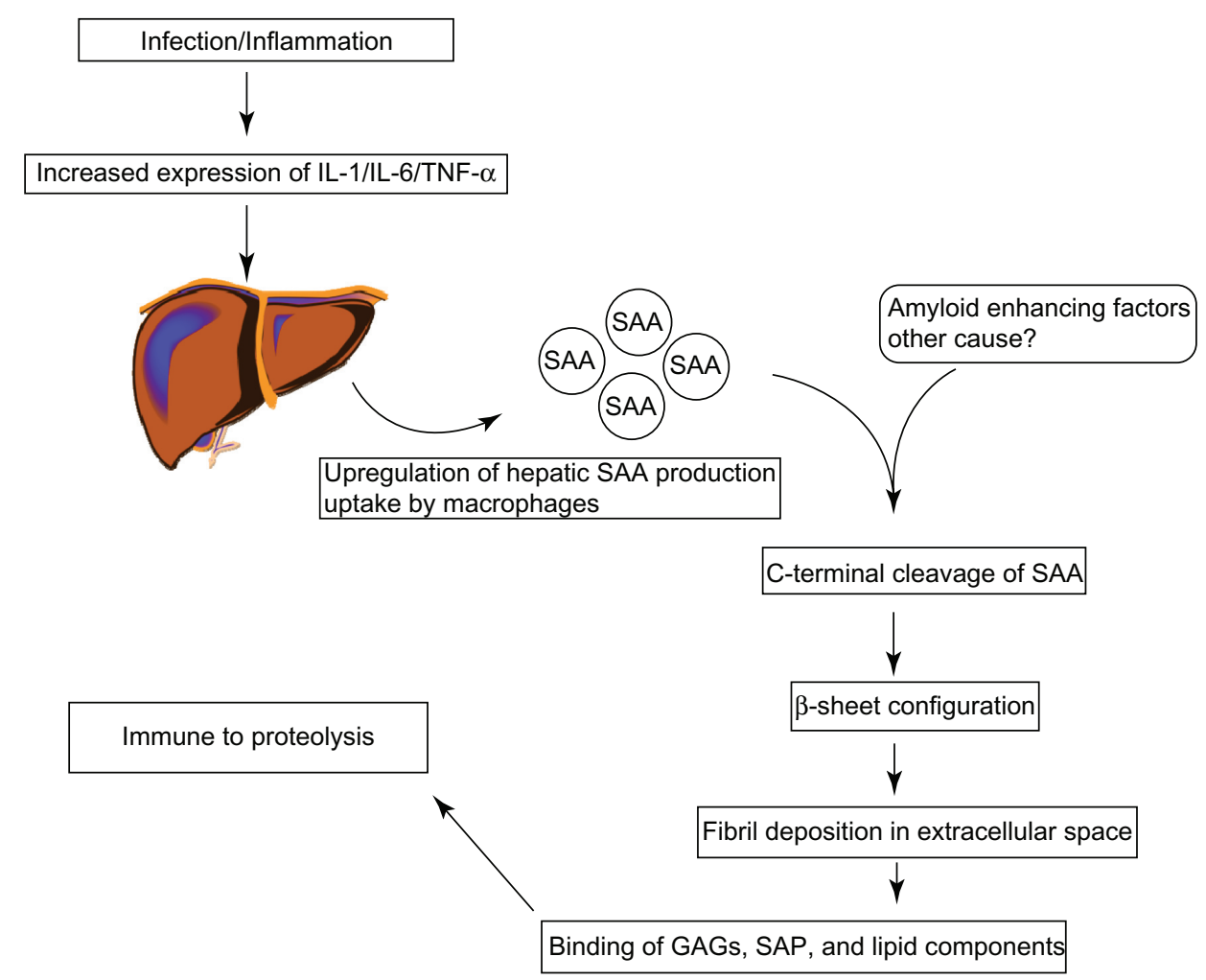

Figure I The pathogenesis of amyloid fibrils.

Abbreviations: SAA, serum amyloid A; IL-I, interleukin-I; IL-6, interleukin 6; TNF- $\alpha$, tumour necrosis factor alpha; GAG, glycosaminoglycan; SAP, serum amyloid P.

between changes in renal function due to changes in size of amyloid deposits. ${ }^{30}$

It has been suggested that amyloidogenic precursor proteins and intermediate filaments have direct toxic effects on the tissues, which are independent of the amyloid deposits. These toxicities might directly contribute to the disease manifestations. This view is supported by observations that proteinuria decreases rapidly after chemotherapy for primary $\mathrm{AL}$ amyloidosis and treatment of the underlying inflammatory condition in secondary AA amyloidosis, leading to a marked reduction in the production of the precursor amyloidogenic proteins. ${ }^{31,32}$ However, in a small published series, there was a lack of improvement in the size of amyloid deposits on repeat kidney biopsy in patients with primary AL amyloidosis following treatment, despite significant improvement in proteinuria. ${ }^{33,34}$ The measured level of serum SAA protein has been shown to correlate with disease activity and is a useful prognostic marker, and the outcome is thought to be favorable if the plasma SAA concentration is kept below $10 \mathrm{mg} / \mathrm{L} .{ }^{35}$

\section{Current treatment options and challenges}

Attenuation of the level of circulating SAA protein by way of treating the underlying inflammatory condition remains the primary strategy in treating AA amyloidosis. The median plasma concentration of SAA in healthy individuals is $3 \mathrm{mg} / \mathrm{L}$, but the concentration can be 650 -fold higher during an acute-phase response. ${ }^{36}$ The relative risk of death amongst patients with a plasma SAA concentration of $>155 \mathrm{mg} / \mathrm{L}$ is 18 times greater than those with a plasma SAA concentration of $<4 \mathrm{mg} / \mathrm{L}$, and four times greater than in patients with an SAA concentration of 4-9 mg/L. ${ }^{3}$ Lachmann et al reported an improvement in renal functions in patients with a median SAA concentration of $6 \mathrm{mg} / \mathrm{L}$ and deterioration in patients with a median SAA concentration of $28 \mathrm{mg} / \mathrm{L} .{ }^{3}$ Proteinuria reduces significantly in patients with AA amyloidosis when the underlying inflammatory disease becomes quiescent. ${ }^{31}$

Chronic pyogenic and granulomatous diseases (particularly tuberculosis) previously accounted for a far higher proportion of cases and were successfully treated with antimicrobial therapy and surgery for those with abscesses and osteomyelitis. Other therapeutic interventions include colchicine, which has been successfully used to treat FMF, thus preventing or treating the associated secondary AA amyloidosis. ${ }^{3,37}$ Conditions previously associated with AA amyloidosis such as Hodgkin's disease have virtually been eliminated as a cause with increasingly effective chemotherapeutic agents. The majority of cases now seen in the 
developed world reflect the increasingly efficient treatment of infectious diseases, and are seen in those with inflammatory arthritides. Regression of amyloid deposits in these patients is dependent upon successful treatment with immunosuppressive strategies or biological agents such as anti-TNF therapies or interleukin-1 receptor antagonists. ${ }^{38,39}$ The increase in use of disease-modifying agents and biological treatments for rheumatic diseases has led to a subsequent decline in the incidence of patients requiring renal replacement therapy for amyloid. ${ }^{40}$

Targeting the production of amyloidogenic proteins is a potentially effective strategy, but achieving adequate control of protein production can prove difficult. In addition, relapse of renal function often occurs rapidly following any subsequent inflammatory stimulus in patients with existing amyloidosis. Murine studies have suggested that the presence of an amyloid-enhancing factor (AEF) fast-tracks further surges of SAA into amyloid formation. ${ }^{41}$ Other potential strategies that have been attempted include targeting of the amyloid deposits themselves. Serum amyloid P (SAP) is a plasma glycoprotein that is bound to the $\beta$-sheets and ubiquitous in all amyloid tissues, regardless of the sub-type. The presence of SAP has formed the basis for a key assessment tool allowing quantification of amyloid deposition in tissues, by the binding of radioisotope-labeled SAP to amyloid deposits. ${ }^{42}$ Therapies targeting SAP have previously been developed that target the SAP-amyloid fibril interaction and allow the removal of SAP by the liver. ${ }^{43}$ SAP monoclonal antibodies have also been developed in murine models and have been shown to reduce visceral amyloid deposits by triggering a complement-dependent macrophage-derived reaction. ${ }^{44}$ Recently, antisense oligonucleotides have also been successfully used to downregulate expression of SAA in animal models. ${ }^{45}$

\section{Introduction to eprodisate}

As mentioned above, sulfated glycosaminoglycans, such as dextran and heparan sulfate, are always associated anatomically with amyloid deposits, regardless of the nature of the protein deposited, and are necessary for the assembly of the fibrils as well as the stability of tissue amyloid deposits. ${ }^{46-49}$ Heparan sulfate is considered to be responsible for the stability of $\mathrm{SAA}_{2}$, which is the immediate precursor to AA amyloid in adopting the $\beta$-sheet structure that is characteristic of the amyloid protein-folding patterns. ${ }^{50}$ Pre-clinical studies using small-molecule anionic sulfonates or sulfates significantly reduced murine splenic AA amyloid progression by disruption of the heparan sulfate- $\beta$-peptide fibril aggregate by competitively binding to the glycosaminoglycan-binding sites, thus inhibiting fibril polymerization. ${ }^{51}$ Four compounds were shown to be significantly effective in a dose-dependent manner in animal models, and of these, 1-3 propanedisulfonic acid disodium salt or eprodisate (NC-503, Kiacta ${ }^{\circledR}$, previously Fibrillex ${ }^{\mathrm{TM}}$, marketed by Neurochem, Laval, Canada), was taken forward to human studies and used in the Phase III eprodisate for AA amyloidosis (EFAAT) trial. Eprodisate is similar in structure to heparan sulfate and is a low molecular weight, negatively charged, sulfonated molecule (Figure 2). ${ }^{51,52}$

\section{Pharmacokinetics safety and efficacy}

Pre-clinical pharmacokinetic studies showed that eprodisate has good bioavailability when administered orally and is not protein-bound. ${ }^{52}$ Pharmacokinetic analysis of Phase I studies involving healthy volunteers showed a high interindividual variability in plasma concentration following oral doses ranging from 100-2400 mg. Maximum plasma concentrations were reached within 15-60 minutes postdose. A plasma half-life of approximately 10-20 hours was estimated from a multiple rising oral dose study. ${ }^{49}$ Eprodisate is primarily excreted by the kidneys and the plasma concentration is increased in patients with renal impairment requiring dose adjustment. ${ }^{49,52}$ Animal studies using eprodisate at a high daily dose of $2 \mathrm{gm} / \mathrm{kg} /$ day over a 10-month period showed that the drug was well tolerated with low toxicity potential and was found to be nonmutagenic. ${ }^{53}$

Eprodisate was assessed in a multicenter, randomized, double-blind, placebo-controlled trial to evaluate its efficacy and safety in patients with AA amyloidosis and renal involvement. ${ }^{54}$ Renal involvement was defined as proteinuria of greater than $1 \mathrm{~g}$ /day or a creatinine clearance of $<60 \mathrm{~mL} /$ minute. Patients were excluded if their creatinine clearance was $<20 \mathrm{~mL} /$ minute or they had renal

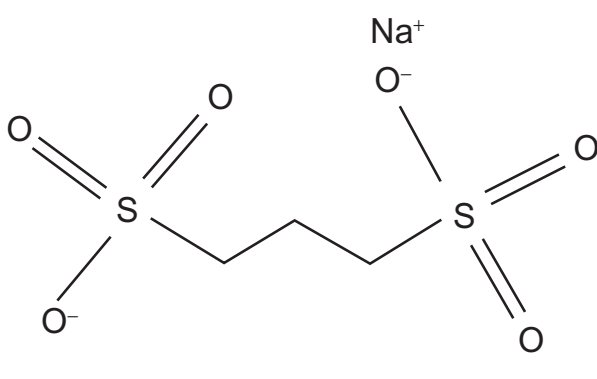

$\mathrm{Na}^{+}$

Figure 2 The chemical structure of I,3 propanedisulfonic acid disodium salt. 
disease attributable to other than AA amyloidosis. Significant liver dysfunction and diabetes were also amongst the exclusion criteria.

One hundred and eighty-three patients were assigned to the treatment drug, or placebo, and were well matched for age, gender and weight. Drug dosages were calculated according to baseline renal function. The study drug was administered orally twice daily at least 1 hour before or 2 hours after a meal. Patients with creatinine clearance rates of less than $30 \mathrm{~mL}$ per minute received a total of $800 \mathrm{mg}$ of eprodisate per day in two divided doses, those with rates of 30-80 mL per minute received a total of $1600 \mathrm{mg}$ per day in two divided doses, and those with rates of more than $80 \mathrm{~mL}$ per minute received a total of $2400 \mathrm{mg}$ of eprodisate per day in two divided doses. Doses were decreased during the study if creatinine clearance decreased. Treatment of the underlying inflammatory disease was determined by the patient's physician. Patients were followed up 4 monthly for a total of 2 years.

The primary endpoint of the study was a composite of decline in renal function or death. Worsening renal function was defined as doubling of serum creatinine, $50 \%$ reduction in creatinine clearance from the baseline, or progression to end-stage renal failure. Of the 183 patients, 124 completed the study. The adverse events were similar between the two groups. There were five deaths in each group during or within 15 days after completion of administration of the study drug. Two patients in the eprodisate group died of ischemic stroke, one patient had nephrotic syndrome as cause of death while one each had gastrointestinal hemorrhage and pneumonia. The deaths in the placebo group were due to ischemic stroke, amyloid cardiomyopathy, bowel perforation, sepsis, and pancytopenia in one patient each. None of the deaths were considered to be related to eprodisate itself.

There was a clear trend towards arresting the decline in renal function in the treatment group compared to the placebo group with a $42 \%$ reduction seen $(0.37-0.93$, $P=0.02$ ), which was independent of baseline renal function or circulating SAA concentration. Urinary protein excretion, however, was not affected. Some discrepancies were evident; the placebo arm had significantly more patients with a higher diastolic blood pressure and had a higher median serum creatinine level. The placebo arm also tended towards higher median SAA and C-reactive protein (CRP) levels although the differences between the two arms were not statistically significant ( $P=0.14$ for both). The treatment arm had significantly more patients with chronic infections (21 versus $9, P=0.01$ ) raising the possibility that treatment with antimicrobial therapy may have partially accounted for some of the effect seen, given that median SAA and CRP levels were lower in this group. The acknowledged mechanism of action of eprodisate means that the glycosaminoglycanamyloid fibril complex is disrupted, thereby preventing formation of new amyloid deposits. This is possibly why renal function in the treatment arm declined more slowly than in the placebo arm. There appeared to be no improvement in the levels of proteinuria in the treatment group suggesting that glomerular damage previously incurred by the kidney was not affected by the putative lack of development of additional amyloid deposits.

\section{The future}

In 2006, Neurochem Inc, announced that a letter had been received from the US Food and Drug Administration requesting further efficacy and safety information that would need to be addressed through additional clinical trials before approval would be given for its use in AA amyloidosis. One-year follow-up data from the original randomized trial revealed that eprodisate continued to be safe, and that comparisons looking at progression to dialysis/ESRD, or the composite endpoint of renal decline and death favored those patients in the treatment arm. ${ }^{55}$ In 2008, it was announced that a second Phase III trial would be initiated as recommended by both European and US regulatory agencies. Recruitment commenced in November 2010 and the estimated date of completion of the study is May 2014. The primary outcome measures are a decrease in creatinine clearance of $40 \%$ from baseline, an increase in serum creatinine of $80 \%$, or progression to end-stage renal disease. ${ }^{56}$

\section{Conclusion}

Clinicians currently have a limited repertoire of therapeutic options when confronted with a patient with AA amyloidosis, although treating the underlying inflammatory condition remains the primary strategy. The preliminary results from Dember et al's study ${ }^{54}$ are certainly encouraging and the results from the second Phase III study will clarify whether or not eprodisate has a place in treating renal amyloid disease. At this stage, it is not known whether using eprodisate as an adjunctive therapy earlier on in the course of disease may affect outcomes, perhaps when SAA levels start to rise consistently above $4 \mathrm{mg} / \mathrm{L}$. Strategies such as eprodisate that are designed to disturb the formation of amyloid fibrils, and other molecular techniques that target the stability of amyloid fibrils offer a new way of treating a potentially devastating condition. 


\section{Disclosure}

The authors report no conflicts of interest in this work.

\section{References}

1. Sipe JD, Benson MD, Buxbaum JN, et al. Amyloid fibril protein nomenclature: 2010 recommendations from the nomenclature committee of the International Society of Amyloidosis. Amyloid. 2010;17(3-4): 101-104.

2. Merlini G, Bellotti V. Molecular mechanisms of amyloidosis. $N$ Engl J Med. 2003;349(6):583-596.

3. Lachmann HJ, Goodman HJ, Gilbertson JA, et al. Natural history and outcome in systemic AA amyloidosis. N Engl J Med. 2007;356(23): 2361-2371.

4. Cania A, Bergesio F, Curciarello G, et al. The Florence Register of amyloidosis: 20 years' experience in the diagnosis and treatment of the disease in the Florence district area. Amyloid. 2011;18 Suppl 1: 81-83.

5. Koivuniemi R, Paimela L, Suomalainen R, Leirisalo-Repo M. Amyloidosis as a cause of death in patients with rheumatoid arthritis. Clin Exp Rheumatol. 2008;26(3):408-413.

6. Gertz MA, Kyle RA. Secondary systemic amyloidosis: response and survival in 64 patients. Medicine (Baltimore). 1991;70(4):246-256.

7. Schnitzer TJ, Ansell BM. Amyloidosis in juvenile chronic polyarthritis. Arthritis Rheum. 1977;20(2 Suppl):245-252.

8. Moroni G, Banfi G, Montoli A, et al. Chronic dialysis in patients with systemic amyloidosis: the experience in northern Italy. Clin Nephrol. 1992;38(2):81-85.

9. Akpolat T, Akpolat I, Kandemir B. Behcet's disease and AA-type amyloidosis. Am J Nephrol. 2000;20(1):68-70.

10. Sattianayagam PT, Hawkins PN, Gillmore JD. Systemic amyloidosis and the gastrointestinal tract. Nat Rev Gastroenterol Hepatol. 2009;6(10):608-617.

11. Tuglular S, Yalcinkaya F, Paydas S, et al. A retrospective analysis for aetiology and clinical findings of 287 secondary amyloidosis cases in Turkey. Nephrol Dial Transplant. 2002;17(11):2003-2005.

12. Berglund K, Thysell H, Keller C. Results, principles and pitfalls in the management of renal AA-amyloidosis; a 10-21 year followup of 16 patients with rheumatic disease treated with alkylating cytostatics. J Rheumatol. 1993;20(12):2051-2057.

13. Goldsmith DJ, Roberts IS, Short CD, Mallick NP. Complete clinical remission and subsequent relapse of bronchiectasis-related (AA) amyloid induced nephrotic syndrome. Nephron. 1996;74(3): $572-576$.

14. Hazenberg BP, van Rijswijk MH. Clinical and therapeutic aspects of AA amyloidosis. Baillieres Clin Rheumatol. 1994;8(3):661-690.

15. Marhaug $G$. Three assays for the characterization and quantitation of human serum amyloid A. Scand J Immunol. 1983;18(4):329-338.

16. Hoffman JS, Benditt EP. Changes in high density lipoprotein content following endotoxin administration in the mouse. Formation of serum amyloid protein-rich subfractions. J Biol Chem. 1982;257(17): 10510-10517.

17. Thorn CF, Lu ZY, Whitehead AS. Regulation of the human acute phase serum amyloid A genes by tumour necrosis factor-alpha, interleukin-6 and glucocorticoids in hepatic and epithelial cell lines. Scand J Immunol. 2004;59(2):152-158.

18. Utsunomiya I, Nagai S, Oh-ishi S. Sequential appearance of IL-1 and IL-6 activities in rat carrageenin-induced pleurisy. $J$ Immunol. 1991;147(6):1803-1809.

19. Ray A, Shakya A, Kumar D, Benson MD, Ray BK. Inflammationresponsive transcription factor SAF-1 activity is linked to the development of amyloid A amyloidosis. J Immunol. 2006;177(4):2601-2609.

20. Gollaher CJ, Bausserman LL. Hepatic catabolism of serum amyloid A during an acute phase response and chronic inflammation. Proc Soc Exp Biol Med. 1990;194(3):245-250.
21. Parmelee DC, Titani K, Ericsson LH, Eriksen N, Benditt EP, Walsh KA. Amino acid sequence of amyloid-related apoprotein (apoSAA1) from human high-density lipoprotein. Biochemistry. 1982; 21(14):3298-3303.

22. Husebekk A, Skogen B, Husby G, Marhaug G. Transformation of amyloid precursor SAA to protein AA and incorporation in amyloid fibrils in vivo. Scand J Immunol. 1985;21(3):283-287.

23. Tennent GA, Lovat LB, Pepys MB. Serum amyloid P component prevents proteolysis of the amyloid fibrils of Alzheimer disease and systemic amyloidosis. Proc Natl Acad Sci US A. 1995;92(10):4299-4303.

24. Li JP, Galvis ML, Gong F, et al. In vivo fragmentation of heparan sulfate by heparanase overexpression renders mice resistant to amyloid protein A amyloidosis. Proc Natl Acad Sci U S A. 2005;102(18): 6473-6477.

25. Gellermann GP, Appel TR, Tannert A, et al. Raft lipids as common components of human extracellular amyloid fibrils. Proc Natl Acad Sci US A. 2005;102(18):6297-6302.

26. Gershoni-Baruch R, Brik R, Zacks N, Shinawi M, Lidar M, Livneh A. The contribution of genotypes at the MEFV and SAA1 loci to amyloidosis and disease severity in patients with familial Mediterranean fever. Arthritis Rheum. 2003;48(4):1149-1155.

27. Cazeneuve C, Ajrapetyan H, Papin S, et al. Identification of MEFVindependent modifying genetic factors for familial Mediterranean fever. Am J Hum Genet. 2000;67(5):1136-1143.

28. Altiok O, Seguret F, Touitou I. MEFV sequence variants and amyloidosis: still an enigmatic question. Hum Mutat. 2003;21(1):96-97.

29. van der Hilst JCH. Recent insights into the pathogenesis of type AA amyloidosis. Scientific World Journal. 2011;11:641-650.

30. Snanoudj R, Durrbach A, Gauthier E, et al. Changes in renal function in patients with familial amyloid polyneuropathy treated with orthotopic liver transplantation. Nephrol Dial Transplant. 2004;19(7): 1779-1785.

31. Elkayam O, Hawkins PN, Lachmann H, Yaron M, Caspi D. Rapid and complete resolution of proteinuria due to renal amyloidosis in a patient with rheumatoid arthritis treated with infliximab. Arthritis Rheum. 2002;46(10):2571-2573.

32. Leung N, Dispenzieri A, Fervenza FC, et al. Renal response after highdose melphalan and stem cell transplantation is a favorable marker in patients with primary systemic amyloidosis. Am J Kidney Dis. 2005;46(2):270-277.

33. Zeier M, Perz J, Linke RP, et al. No regression of renal AL amyloid in monoclonal gammopathy after successful autologous blood stem cell transplantation and significant clinical improvement. Nephrol Dial Transplant. 2003;18(12):2644-2647.

34. Kyle RA, Wagoner RD, Holley KE. Primary systemic amyloidosis: Resolution of the nephrotic syndrome with melphalan and prednisone. Arch Intern Med. 1982;142(8):1445-1447.

35. Gillmore JD, Lovat LB, Persey MR, Pepys MB, Hawkins PN. Amyloid load and clinical outcome in AA amyloidosis in relation to circulating concentration of serum amyloid A protein. Lancet. 2001; 358(9275):24-29.

36. Ledue TB, Weiner DL, Sipe JD, Poulin SE, Collins MF, Rifai N. Analytical evaluation of particle-enhanced immunonephelometric assays for C-reactive protein, serum amyloid A and mannose-binding protein in human serum. Ann Clin Biochem. 1998;35(Pt 6):745-753.

37. Gillmore JD, Hawkins PN, Pepys MB. Amyloidosis: a review of recent diagnostic and therapeutic developments. Br J Haematol. 1997;99(2): 245-256.

38. Keersmaekers T, Claes K, Kuypers DR, de Vlam K, Verschueren P, Westhovens R. Long-term efficacy of infliximab treatment for AAamyloidosis secondary to chronic inflammatory arthritis. Ann Rheum Dis. 2009;68(5):759-761.

39. Fernandez-Nebro A, Olive A, Castro MC, Varela AH, Riera E, Irigoyen $\mathrm{MV}$, et al. Long-term TNF-alpha blockade in patients with amyloid A amyloidosis complicating rheumatic diseases. Am J Med. 2010;123(5):454-461. 
40. von Hutten H, Mihatsch M, Lobeck H, Rudolph B, Eriksson M, Rocken C. Prevalence and origin of amyloid in kidney biopsies. Am J Surg Pathol. 2009;33(8):1198-1205.

41. Kisilevsky R, Young ID. Pathogenesis of amyloidosis. Baillieres Clin Rheumatol. 1994;8(3):613-626.

42. Hawkins PN, Lavender JP, Pepys MB. Evaluation of systemic amyloidosis by scintigraphy with 123I-labeled serum amyloid P component. N Engl J Med. 1990;323(8):508-513.

43. Pepys MB, Herbert J, Hutchinson WL, et al. Targeted pharmacological depletion of serum amyloid $\mathrm{P}$ component for treatment of human amyloidosis. Nature. 2002;417(6886):254-259.

44. Bodin K, Ellmerich S, Kahan MC, et al. Antibodies to human serum amyloid P component eliminate visceral amyloid deposits. Nature. 2010;468(7320):93-97.

45. Kluve-Beckerman B, Hardwick J, Du L, et al. Antisense oligonucleotide suppression of serum amyloid A reduces amyloid deposition in mice with AA amyloidosis. Amyloid. 2011;18(3):136-146.

46. Snow AD, Willmer J, Kisilevsky R. A close ultrastructural relationship between sulfated proteoglycans and AA amyloid fibrils. Lab Invest. 1987;57(6):687-698.

47. Lyon AW, Narindrasorasak S, Young ID, et al. Co-deposition of basement membrane components during the induction of murine splenic AA amyloid. Lab Invest. 1991;64(6):785-790.

48. Stenstad T, Magnus JH, Husby G. Characterization of proteoglycans associated with mouse splenic AA amyloidosis. Biochem J. 1994; 303(Pt 2):663-670.
49. Kisilevsky R. The relation of proteoglycans, serum amyloid $P$ and apo E to amyloidosis current status, 2000. Amyloid. 2000;7(1):23-25.

50. McCubbin WD, Kay CM, Narindrasorasak S, Kisilevsky R. Circular-dichroism studies on two murine serum amyloid A proteins. Biochem J. 1988;256(3):775-783.

51. Kisilevsky R, Lemieux LJ, Fraser PE, Kong X, Hultin PG, Szarek WA. Arresting amyloidosis in vivo using small-molecule anionic sulfonates or sulfates: implications for Alzheimer's disease. Nat Med. 1995;1(2):143-148.

52. Gandhi NS, Mancera RL. Heparin/heparan sulfate-based drugs. Drug Discov Today. 2010;15(23-24):1058-1069.

53. Manenti L, Tansinda P, Vaglio A. Eprodisate in amyloid A amyloidosis: a novel therapeutic approach? Expert Opin Pharmacother. 2008;9(12): 2175-2180.

54. Dember LM, Hawkins PN, Hazenberg BP, et al. Eprodisate for the treatment of renal disease in AA amyloidosis. N Engl J Med. 2007;356(23): 2349-2360.

55. Neurochem. Neurochem submits a complete response to FDA approvable letter for Kiacta. 2006. [cited November 22, 2011]. Available from: http://drugs.com/nda/kiacta_061016.html.

56. CT Development America, Inc. Efficacy and safety study of KIACTA in preventing renal function decline in AA amyloidosis. In: ClinicalTrials. gov [website on the Internet]. Bethseda, MD: US National Library of Medicine; 2011. [updated December 6, 2011]. Available from: http:// clinicaltrials.gov/ct2/show/NCT01215747?term=eprodisate\&rank=1 . NLM identifier:NCT01215747. Accessed February 7, 2012.

\section{Publish your work in this journal}

The International Journal of Nephrology and Renovascular Disease is an international, peer-reviewed open-access journal focusing on the pathophysiology of the kidney and vascular supply. Epidemiology, screening, diagnosis, and treatment interventions are covered as well as basic science, biochemical and immunological studies. The journal welcomes original research, clinical studies, reviews \& evaluations, expert opinion and commentary, case reports and extended reports. The manuscript management system is completely online and includes a very quick and fair peerreview system, which is all easy to use. Visit http://www.dovepress.com/ testimonials.php to read real quotes from published authors 